J. Clin. Chem. Clin. Biochem.

Vol. 14, 1976, pp. 395-399

\title{
Clinical Significance of Urinary Carcino-Embryonic Antigen Estimations During the Follow-Up of Patients with Bladder Carcinoma or Previous Bladder Carcinoma
}

\author{
Clinical Evaluation of Carcino-Embryonic Antigen, III.
}

\author{
By J.-P. Persijn, C. B. Korsten, J. J. Battermann, A. H. Tierie and J. Renaud
}

From the Department of Clinical Chemistry (Head Dr. J. P. Persijn), the Department of Radiotherapy (Head Professor Dr. K. Breur) and the Department of Urology (Head Dr. J. Renaud), Netherlands Cancer Institute, Amsterdam

(Received December 19, 1975/May 16, 1976)

Summary: Urinary carcino-embryonic antigen (CEA) was measured in a follow-up study of 101 bladder carcinoma patients. Urinary CEA estimation during follow-up appears to be of clinical value. Negative results can be interpreted only in relation to previously increased values. Positive results are of value in retrospect when combined with negative data, e.g in evaluation of suspicious bladder changes and as an early indication of renewed tumour growth. Increased CEA levels in urines from patients with urinary infection rapidly decline once the infection is cured.

Klinische Bedeutung des carcino-embryonalen Antigens, 3. Mitteilung Bewertung der Bestimmung des carcino-embryonalen Antigens im Urin während der Verlaufskontrolle bei Patienten mit Blasenkrebs.

Zusammenfassung: Bei 101 Patienten wurden die Konzentrationen des carcino-embryonalen Antigens (CEA) im Urin im Vergleich mit den Therapie-Effekten bewertet. Hieraus ließ sich schließen, daß der CEA-Bestimmung in dieser Hinsicht klinische Bedeutung beigemessen werden kann. Normale CEA-Werte können klinisch nur interpretiert werden, wenn diese in Folge von vorher erhöhten Werten gefunden worden sind. Erhöhte Werte haben nur Aussagekraft im Zusammenhang mit früher gemessenen normalen Werten, z. B. in der Auswertung von verdächtigen Prozessen in der Blase und als ein frühzeitiger Hinweis auf erneutes Tumorwachstum.

\section{Introduction}

Since 1972 several authors $(1-6)$ have shown that increased urinary $\mathrm{CEA}^{1}$ ) levels can occur in association with bladder carcinoma.

In a previous paper (6) we studied urinary CEA levels in several groups of subjects with and without bladder carcinoma. We tried to correlate several parameters of the bladder tumour with urinary CEA levels. In addition, efforts were made to gain better insight into the origin of urinary CEA. It was concluded that the assay of CEA in urine is helpful in detecting a tumour mass in the bladder.

In this paper we try to evaluate whether measurement of urinary CEA can be clinically helpful during follow-up of patients with bladder carcinoma or previous bladder carcinoma.

1) Abbreviation: CEA = carcino-embryonic antigen.

\section{Materials and Methods}

Unless stated otherwise urines were collected during cystoscopy. A culture was made of a part of each sample. Another part of the sample was dialysed, using cellulose acetate tubing for $\mathbf{4}$ hours against phosphate buffered saline $(50 \mathrm{mmol} / 1$ phosphate; $0.1 \mathrm{mmol} / 1 \mathrm{~K}_{2}$ EDTA; $\mathrm{pH}$ 7.4). The dialysed portions were stored frozen until assay of CEA. Cultures of the urines were grown on gel plates within a few hours of collection. Urinary infection was considered to be present if more than $10^{8}$ colonies/1 were found. CEA was measured in duplicate by the procedure described in a previous paper. Assays were performed in dialysed urines, undiluted as well as diluted 1:2 with phosphate-buffered saline (7). The upper limit of normal urinary CEA is $30 \mu \mathrm{g} / \mathrm{l}(6)$.

\section{Patients}

In 101 patients, 82 male and 19 female, who suffered or had previously suffered from bladder carcinoma, CEA levels were measured several times during follow-up. The patients were aged between 28 and 87 years. The tumours were classified and staged according to the UICC criteria (8). Unless stated otherwise, the patients were free of urinary infection at the time of urine collection. In all cases urinary CEA was estimated without knowledge of the clinical status of the subject involved. 
The diagnosis was made and treatment given without reference to the CEA values. Results of treatment were assessed and recorded independently of the results of the CEA assays.

\section{Results}

According to their CEA pattern the patients were divided into 4 groups.

\section{Patients whose uninary CEA was and remained normal} This group comprises 70 patients:

a. 63 patients, showing normal CEA levels on several occasions, were tumour-free whenever urinary CEA was measured. Some showed papillomas, i.e. non-invasive bladder carcinoma or a radiation ulcus in the bladder on some occasions of urine collection.

b. One patient had a normal CEA level in urine on two different occasions at an interval of two months. However, no tumour was found in the bladder the first time, the second time a tumour had grown.

c. In 6 patients CEA in urine was normal on several occasions. At the onset'of the period studied, a bladder tumour was found in these patients. Later results corresponded to tumour-free situations (after therapy).

\section{Patients who showed a rise of urinary CEA level} during follow-up after an initial normal value

This group consists of 10 patients:

a. 7 patients with initial normal CEA levels were found to be free from tumours. In the course of time increased CEA levels occurred. Clinical data revealed that these increased values corresponded with regrowth of tumours.

b. In three patients CEA changed from normal to elevated values during follow-up. These patients are here described separately because tumour growth could not be established with certainty at the time of increased CEA values. In the first case CEA had risen to a slightly positive value $(32 \mu \mathrm{g} / \mathrm{l})$.

A bleeding spot was seen in the bladder, but malignancy was not confirmed. After coagulation CEA decreased to normal.

In the second case CEA rose to $52 \mu \mathrm{g} / \mathrm{l}$. At that time the bladder showed a few dubious spots.

In the third case CEA excretion changed from negative to $60 \mu \mathrm{g} / \mathrm{l}$. In this patient the mucosa of the bladder showed changes apparently due to previous irradiation, performed years ago, but no tumour was found.

\section{Patients with increased urinary $C E A$, decreasing to normal levels}

This group comprises 15 patients.

a. In 9 patients a tumour was observed in the bladder at the time of the initial increased CEA levels.

During follow-up (after treeatment) normal CEA amounts were measured and the tumour mass had disappeared.

b. In three patients with high urinary CEA levels the bladder contained a tumour, but an infection of the urinary tract was also present. Subsequent CEA measurements showed normal values in each case and in each patient tumour and urinary infection had disappeared.

c. With a view to the course of the urinary CEA during and after urinary infection, three patients with urinary infection but without bladder tumour were studied. It is to be noted that these patients had previously had a bladder carcinoma. The CEA levels were $>300 \mu \mathrm{g} / 1,260 \mu \mathrm{g} / \mathrm{l}$ and $72 \mu \mathrm{g} / \mathrm{l}$. Ten, 6 and $1 \frac{1}{2}$ months later, respectively, CEA was measured again and found to be normal. The urinary infection had disappeared.

\section{Patients with persistently increased urinary CEA levels} This group includes 6 patients:

a. In one patient without urinary infection an increased CEA concentration was found twice ( 88 and $200 \mu \mathrm{g} / \mathrm{l}$, respectively), at an interval of 12 months. At both CEA measurements the bladder contained a tumour. It is of interest to note that intercurrent examination after treatment disclosed that the bladder was tumour-free. At that time no CEA assay was made.

b. One patient showed a high CEA level in the urine, and cystoscopy revealed a tumour in the bladder. The patient was treated by irradiation, resulting in subjective improvement for 7 months. Estimations performed in urine collected $91 / 2$ and $12^{1} / 2$ months later, respectively, showed decreased but still elevated levels. At the former time necrotic tumour tissue was observed in the bladder. Unfortunately, the result of the urinary culture is unknown. Clinical examination three months later revealed renewed tumour growth in the bladder. Urinary infection was absent.

c. In one patient without urinary infection an increased CEA level was found twice $(51 \mu \mathrm{g} / \mathrm{l}$ and $45 \mu \mathrm{g} / \mathrm{l}$, respectively) at an interval of 5 months. Prior to the first measurements there had been a period (8 months) of subjective improvement after irradiation, except for the last $\overline{7}$ weeks. A bleeding vessel was found in the bladder at the time of the first CEA measurement. A month later a tumour 
mass was observed in the bladder. The same was observed at the second CEA measurement.

d. In one patient there was evidence that both urinary infection and bladder tumour were present. The urinary CEA level was $105 \mu \mathrm{g} / 1$. A few weeks later the CEA was still increased $(85 \mu \mathrm{g} / \mathrm{l})$. Examination that the urinary infection had been cured.

e. In two other patients CEA was elevated while a urinary infection was present, but no tumour was found in the bladder. Later, the CEA was still increased, but the urinary infection had been cured. However, at that time the bladder still contained a tumour.

\section{Case histories}

A few case histories will serve to illustrate the above data. been irradiated 2 years earlier for a bladder carcinoma, stage $T_{4}$, had a radiation ulcus in the bladder at the first CEA measurement $(\leq 30 \mu \mathrm{g} / \mathrm{l})$. Five months later an increased urinary CEA was observed ( $38 \mu \mathrm{g} / 1$, midstream urine). Unfortunately no cytoscopic data were available. Two weeks later, urinary CEA was $71 \mu \mathrm{g} / 1$ and at that time cystoscopy revealed

Case no. 2 (fig. $1 \mathrm{~b}$ ) depicts the course of urinary CEA levels in patient $S$., a woman aged 63 , whose bladder tumour (stage $T_{2}$ ) had been surgically removed a month before the onset of the period. At the first CEA measurement $(\leq 30 \mu \mathrm{g} / \mathrm{l})$ she had an ulcus in the bladder. A few months later excretion of urinary CEA had increased to $49 \mu \mathrm{g} / \mathrm{l}$. At that time a tumour with a diameter of $1 \mathrm{~cm}$ was found in the bladder. Irradiation resulted in disappearance of the tumour and subsequent CEA estimation gave a normal result.

Case no. 3 (fig. $1 \mathrm{c}$ ) describes patient J., a man aged 63. Irradiation of the bladder tumour (stage $\mathrm{T}_{4}$ ) had been performed 8 months before. At the time indicated by the onset of the period shown in the figure; CEA in the urine was normal. Cystoscopy failed to reveal the presence of a tumour.

The same observations were repeated five months later. However, 5 months after the second measurement CEA in the urine had increased to $177 \mu \mathrm{g} / \mathrm{l}$. At that time the bladder contained a tumour and the patient also had a cystitis. Four months later the urinary CEA concentration was $54 \mu \mathrm{g} / \mathrm{l}$. The tumour was still present, but the cystitis had disappeared.

Case no. 4 refers to patient d. V., a man aged 58, who had been irradiated for bladder carcinoma (stage $T_{3}$ ) 5 years before the onset of the period illustrated in figure $1 \mathrm{~d}$. At the times of the first and second CEA measurements the bladder was found to be free of tumour. A year later, CEA was elevated and at that time a bleeding tumour with a diameter of $2-3 \mathrm{~cm}$ was observed.

Case no. 5 refers to pạtient $H$. a 67-year-old man, whose bladder carcinoma had been diagnosed and treated elsewhere 2 years before the first CEA measurement, shown in figure 2a. About a month before the time of the assay the diagnosis was reconfirmed and the tumour classified as $\mathrm{T}_{4}$. At the time of the first CEA estimation $(46 \mu \mathrm{g} / \mathrm{l})$ the bladder contained a tumour with a diameter $>5 \mathrm{~cm}$. Immediately after this measurement irradiation was started. During irradiation CEA was measured twice (45 and $98 \mu \mathrm{g} / \mathrm{l}$, respectively). The bladder was not examined for tumour. Seven months later urinary CEA was normal. The bladder was free from tumour. revealed that a bladder tumour was present and

Case no. 1. Patient v. E. (fig. 1 a), a 63-year-old man, who had a tumour with a diameter of $3-5 \mathrm{~cm}$.

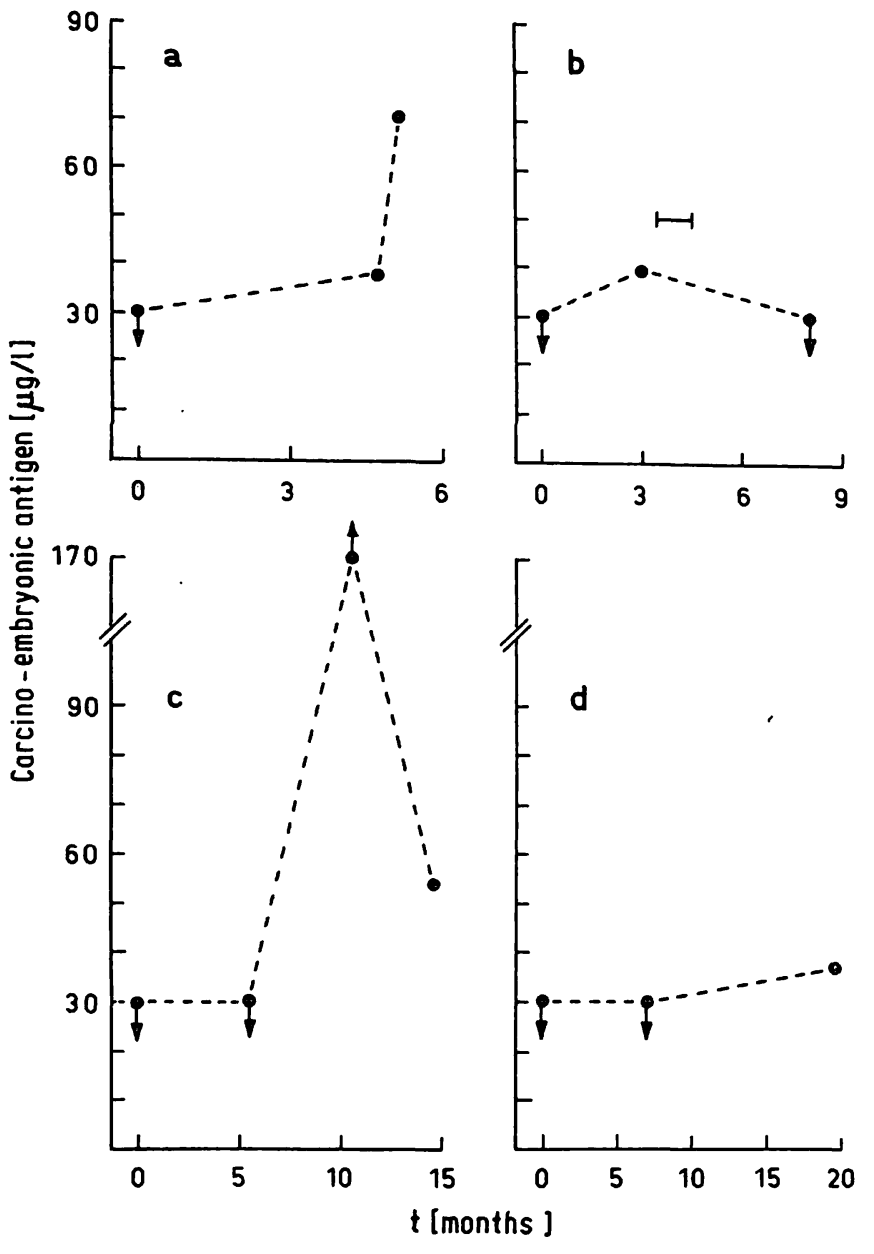

Fig. 1. Variation with time of urinary CEA.

The sign $\longmapsto$ denotes period of irradiation. See also text.
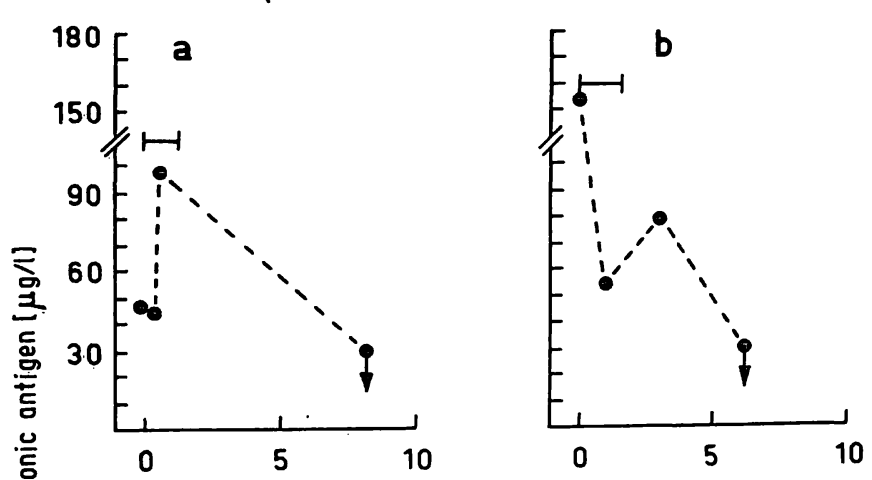
Case no. 6. Patient v. B. (fig. 2b), a 58-year-old man, excreted $155 \mu \mathrm{g} / \mathrm{l} \mathrm{CEA}$. The diameter of the tumour was $>5 \mathrm{~cm}$ (stage $T_{3}$ ). During irradiation, while the tumour was still present, CEA had decreased to $55 \mu \mathrm{g} / 1$. Two months later, while CEA was $81 \mu \mathrm{g} / \mathrm{l}$, the bladder contained necrotic tumour tissue. Three months later CEA had decreased to normal. The bladder was found to be free from tumour at that time.

Case no. 7. Patient F. (fig. 2c), a 62-year-old man, suffering from a bladder tumour with a diameter $>5 \mathrm{~cm}$ (stage $T_{3}$ ), excreted $45 \mu \mathrm{g} / \mathrm{l}$ CEA in urine. Four months later, after irradiation, the tumour had disappeared. The bladder contained a few papillomas and CEA in urine was normal. Four months after this measurement CEA had increased to $35 \mu \mathrm{g} / \mathrm{l}$; the bladder showed no tumour. A month later some bleeding vessels in the bladder had to be coagulated. Again 4 months later, CEA was normal and the bladder showed a small papilloma.

Case no. 8. Patient B., a man aged 59, is illustrated in figure $2 \mathrm{~d}$. At the time of the first CEA measurement $(87 \mu \mathrm{g} / \mathrm{l})$ a tumour (stage $T_{4}$ ) with a diameter of $12 \mathrm{~cm}$ was found in the bladder. Six months later after irradiation, cystoscopy showed a small amount of residual necrotic tumour tissue. Urinary CEA was normal. About 3 months later the bladder still contained some tumour. At this time the patient's history suggested, that renewed tumour growth might be present. CEA was slightly increased $(32 \mu \mathrm{g} / \mathrm{l})$. The tumour was coagulated. Later CEA results, after 4 and 10 months, respectively, were within the normal range. The bladder was free from tumour.

\section{Discussion}

This is the first published study on the serial estimation of urinary CEA levels in relation to the clinical situation during a follow-up on bladder carcinoma. In a previous report (6) it was stated that false-negative results (i.e CEA values $\leq 30 \mu \mathrm{g} / \mathrm{l}$ ) can be found in the presence of a bladder tumour. This phenomenom was also observed in this study (Results, $1 \mathrm{~b}$ and $1 \mathrm{c}$ ).

Consequently a single negative result of a CEA assay in urine does not add essential information on the patient's clinical condition. From the results of this study it appears, however, that negative results do have a value if they follow previously estimated positive values. They indicate successful therapy of the bladder carcinoma. Initial negative results may also be of value in retrospect, if followed by increased CEA levels. In these cases an elevated value indicates recurrence or reactivation of tumour growth in the bladder (see Results, 2a). Let us also consider in this respect figure $1 \mathrm{a}$, illustrating detection of a bladder tumour by measurement of urinary CEA, two weeks before cystoscopy. Cystoscopy is regularly carried out during follow-ups on bladder carcinoma. It seems to be important to estimate urinary CEA levels several times between two cystoscopies. In a number of cases this may lead to earlier discovery of recurrence of the bladder tumour.

Positive data in this study were nearly always related to tumour growth in the bladder once urinary infection was excluded. A few cases in which this relation is not so obvious merit some attention. In one patient we found a slightly elevated CEA value, but no tumour mass or any other change in the bladder (fig. 2c). A month later some bleeding vessels in the bladder had to be coagulated, which possibly indicated tumour growth in the bladder; this could explain the intermediate CEA rise. In a few cases increased urinary CEA was related to suspicious lesions in the bladder (Results, $2 \mathrm{~b}$ and $4 \mathrm{c}$ ).

It seems justifiable to assume that the increased urinary CEA in the cases just mentioned reflects the presence of a tumour. Additional support can be found in the data on the patient described under Results $4 \mathrm{c}$, in whom a tumour was observed a month after the finding of an increased CEA. In another patient (Results, $2 \mathrm{~b}$ third case), no relation between increased urinary CEA level and tumour presence was demonstrable. The only abnormality observed in the bladder of this patient was a change in the mucosa due to irradiation.

A few results indicate (fig. $2 a$ and $b$ ) that disintegration - of the tumour cells may probably cause a short rise of the CEA level. An important complication in the interpretation of urinary CEA levels is the appearance of urinary infection (1-6). The influence of infection on the results is also clearly shown in Results (section 3b, 4d, 4e and fig. 1c). It is important to know how long the CEA level remains increased after disappearance of a urinary infection, as measured by culture. The results (section $3 c)$ suggest that elevation of CEA does not extend over a long period. The data obtained shortly after a cured infection can therefore be considered a rather reliable aid in the diagnosis of bladder tumour. The question arises in how many patients whose urinary CEA has returned to normal after successful therapy, recurrence of the tumour is reflected by a rise of urinary CEA. The question is prompted by the fact that a previous study (6) revealed that $47 \%$ of bladder carcinoma patients have normal urinary CEA. Long-term follow-up studies are required to answer this question. At this time we tend to conclude that CEA levels which decrease from elevated to normal or vice versa reflect progression or regression of malignant processes in the bladder. The urinary CEA assay can therefore be helpful in assessing adequacy of treatment in patients with bladder carcinoma. As such it will be an indispensable adjunct to cystoscopy and other clinical means to judge the patient's condition. Regular measurement of urinary CEA may prevent a delay in adequate treatment.

\section{Acknowledgement}

The authors are indebted to Dr. B. N. F. N. van Bunningen, Dr. F. Dekking, Dr. J. F M. Delemarre and Dr. J. van der Noordaa for support and critical remarks. The authors gratefully acknowledge the skillful help of Mrs. $D . S$. Dijkstra. Mrs. C. Kosterman, Mrs. A. de Wildt and Miss R. H. L. de Wit in performing the assays, the valuable assistance of Mrs. $M$. Bijvoets, Miss $A$. Pot and Mrs. L. Veerman in assembling the urine samples and the valuable assistance of Miss $A$. Baas in recording the clinical data.

The "Praeventiefonds" provided financial support for this study. A grant was received from the Maurits and Anna de Kock Fund. 


\section{Addition to the proof}

After submitting our paper two articles, Wahren, B., Edsmyr, F. \& Zimmermann R. (1975) Cancer 36, 1490-1495 and Fraser, R. A., Ravry, M. J., Sugura, J. W. \& Go, V. L. W., (1975) J.

\section{References}

1. Hall, R. R., Laurence D. J. R., Darcy, D., Stevens, U., James, R., Roberts, S. \& Neville, A'M. (1972). Brit. Med. J. 609-611.

2. Hall, R. R., Laurence, D. J. R., Neville, A. M. \& Wallace, D. M. (1973). Brit. Urol., 45 88-92.

3. Neville, A. M., Nery, R., Hall, R. R., Turberville, C. \& Laurence, D. J. R. (1974). Brit. J. Cancer, 28, Suppl. I, 198-207.

4. Coombs, G. B., Hall, R. R., Laurence. D. J. R. \& Neville, A. M. (1975). Brit. J. Cancer, 31, 135-142.
Urology 14, 226-229, came to our attention dealing with CEA in patients with bladder carcinoma which confirm our results.
5. Guinan, P., John, T., Sadoughi, N., Ablin, R. J. \& Bush, I. (1974). J. Urol., $111,350-352$.

6. Korsten, C. B. Persijn, J. P., Renaud, J. \& Houtzager, C. A. M. (1976), this J., 14, 389-393.

7. Persijn, J. P. \& Korsten, C. B. (1976), this J., 14, 377-387.

8. U.I.C.C., T.N.M. Classification of malignant tumours, Geneva 1968.
Dr. J.-P. Persijn

Antoni van Leeuwenhoek Ziekenhuis Plesmanlaan 121

Amsterdam 
